\title{
National Youth Survey-2012-13: Health profile and risk behaviors of the Sinhalese, Buddhist Unmarried Youth Stratum
}

\author{
N I Thalagala ${ }^{1}$, A.Lokubalasooroya ${ }^{2}$, M.N. Danansuriya ${ }^{3}$, S. P. Godakandage ${ }^{4}$
}

\begin{abstract}
\section{Objectives}

This article summarizes the preliminary findings of the National Youth Health Survey 2013, which aimed to assess the current health concerns of Sri Lankan youths and the factors influencing youth risk behaviors.
\end{abstract}

\section{Design, setting and sample}

The National Youth survey is a cross sectional descriptive survey. This analysis focusses an initial data taken from a stratified random cluster sample of 925 subjects, who represent the Sinhalese Buddhist youths of Sri Lanka.

\section{Methods \& measurements}

Data were collected using a self-administered questionnaire applied in the community. Data on socio demographic details, physical health, mental health, life styles, substance abuse, sexual behaviors, and knowledge on sexual and reproductive health were gathered.

\section{Results}

Nearly, $40 \%$ of youths were still schooling and further $19 \%$ were following higher education. Almost quarter of youths were idling at home without engaging in gainful work or education. One fifth of youths did not attend school beyond secondary level. Around $16 \%$ of them were not feeling happy about life, around $19 \%$ felt life was not worth living and $6 \%$ had strong suicidal feelings. Approximately $32 \%$ males and $2 \%$ females had ever smoked and $38 \%$ males and $3.2 \%$ females reported ever having taken alcohol. Nearly $19 \%$ percent males and $7 \%$ females used abusive substances. Twelve percent males and $3 \%$ females admitted ever having sex.

\section{Conclusion}

A considerable risk behavior and health burden is prevalent among youths.

Key words : Youth, health, risk behaviors.

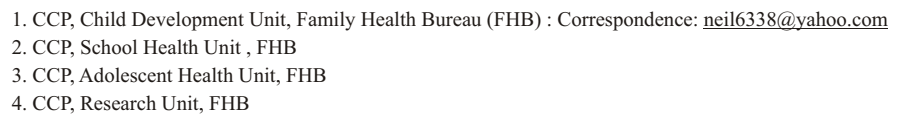




\section{INTRODUCTION}

Youth is considered as the period between 15 to 24 years[1]. At present, approximately 3.2 million youths account for $15.3 \%$ of Sri Lankan population[2]. Of them the majority $(77 \%)$ are Sinhalese Buddhists [3].Rapidly changing reproductive vigor, physical and psychological changes of youth, often make them vulnerable in many respects. The common susceptibilities include substance abuse, unprotected sexual encounters, unwanted pregnancies, sexual abuse, accidents, violence, sexually transmitted disease including HIV/AIDS, mental stress and deliberate self-harm [4]. The impact of these vulnerabilities of youth can be exaggerated, if the youth is from poor segments of society, unemployed, lives alone away from parents, inexperienced and lacks the essential knowledge on important life concerns such as sexuality and reproduction related matters[5].

A national survey conducted in 2004[6, 7] indicated that around $32 \%$ of male youth and $6.8 \%$ female youth has ever smoked and $40 \%$ male youth and $15 \%$ female youth has ever taken an alcoholic drink. Mood altering drugs were ever used by $3 \%$ of male youth and $2 \%$ of female youth respectively. Eighteen percent male youth and $4 \%$ female youth reported ever having sexual intercourse. United States' youth risk surveillance report 2011 indicated that of youth lived in the United States around $45 \%$ has ever smoked, $71 \%$ has ever used alcohol and $47 \%$ has had at least one sexual encounter [4].

The youth's leadership and participation is vital for a country's un-interrupted progress as they should be healthy and be ready to undertake the responsibilities borne by aging citizens. Hence, ensuring positive health and wellbeing of youth through appropriate health promotion strategies becomes an essential prerequisite for any country's development agenda [8]. The nature and extent of youth specific problems and desirable strategies to overcome them may vary by contexts in which they occur [9]. Hence, understanding of specific nature of youth problems becomes an essential requirement before finalizing the action frameworks related to youth health and wellbeing.

Literature survey revealed only 2 national surveys on youth issues in Sri Lanka, which were conducted in the year $2004[6,7]$ and in year 2008 [10]. Thereafter, no national level inquiry on contextual profiles and problems of Sri Lankan youths has been carried out. The Family Health Bureau of Ministry of Health Sri Lanka, in collaboration with and UNICEF and UNFPA, currently conduct a large scale survey on youths in Sri Lanka. This article summarizes the preliminary findings of this survey and focus on socio demographic profile of youths, their physical health and relevant life styles, mental health, prevalence of substance abuse, mental health, and sexual behaviorsamong Sinhalese Buddhists youths in Sri Lanka. It also assesses the factors influencing selected risk behaviors of them.

\section{METHODS}

The national youth survey study population was divided in to 3strata: North \& East provinces, estate sector, and other areas of the country. The youth focused in this article were from the sector identified as other areas. The sample studied constitute a group of 925 youths who were the initial consecutive members of the multistage cluster sample of the national survey. All of them were Sinhalese, Buddhists and were unmarried. The clusters were identified within the randomly selected census blocks used for the 2011 Sri Lankan national census. One cluster consisted of 20 youths the of 15- 24 year old age group. Descriptive estimates estimated by a sample of 925 subjects are capable of having a minimum absolute precision of $4 \%$, given a confidence level of $95 \%$ and design effect of 2 . A youth in the sampling frame was considered as eligible, provided that he or she had been living in the area for more than 6 months and was consenting to be included in the sample. The youth, who may not 
have adequate capacity to provide valid information due to a condition such as a mental illness or mental retardation was excluded.

The survey sought information on level of education, income, occupation, physical health, life styles, mental health, substance use behaviors, reproductive health knowledge, and sexual behaviors.

A preliminary population enumeration within the selected sampling blocks was carried out with the help of field Public Health Midwives (PHMs). The enumeration lists were used to preparea list of eligible youths in selected census blocks. Whenever, an eligible youth was found in these households, the area PHM informed a household member about the potential selection of this youth as a subject of the survey. A cluster of 20youths (10 from 15-19 year age group and another 10 from 20-24 year age group) were randomly identified from the list. A trained investigator couple (a male and a female in their youth) were sent to selected households for data collection. They were introduced to the household members by area PHMs. As many sensitive matters were questioned, a selfadministered questionnaire was used for data collection. The male and female investigatory introduced the questionnaire to the male and female youth respectively. After explaining purpose of the survey, obtaining written informed consent and preliminary answering instructions were given, youths were asked to fill the questionnaire by themselves. However, if the selected youth was not a literate person, the investigator filled the questionnaire after interviewing him or her. In both occasions the other members of the family were requested to remain away to ensure privacy. On average 30 to 45 minutes were spent for the collection of data from a youth. Filled data sheets were kept in safe custody and sent to the center for analysis. The ethical approval for this study was obtained from the ethical review committee of the Faculty of Medical Sciences, University of Sri Jayewardenepura.

\section{Statistical analysis}

Prevalence estimates were summarized as percentages along with $95 \%$ confidence intervals. Binary logistic regression was used to identify the factors influencing 4 selected risk behaviors of youths. Four separate models were run and odds ratios and their $95 \%$ confidence intervals were reported as measures of strength of association. EPIDATA software [11] was used for the data base compilation. The analysis was carried out using STATA10 software [12].

\section{RESULTS}

\section{Socio demographic profile of the sample}

This analysis focused on a group of 925 Sinhalese, Buddhist unmarried youths. Fifty two point five percent of them were females. Their ages ranged from 15 to 24 years with mean age of 18.7 (SD 2.6) months. The majority were from rural areas, while $25.6 \%$ were from the urban sector. Around $38.2 \%$ youths were still schooling, and further $18.7 \%$ were following some form of continuing education. About $9.5 \%$ are having full time jobs, while $8.2 \%$ were having part time jobs. Nearly, quarter $(25.4 \%)$ of them were passing time at home and not engaged in productive work. Educational level of the youths, who are currently above the school going age of 19 years $(n=482)$, was analyzed to study the average level of school education of youths. Of them, only one youth, has never been to a school. Another $1.1 \%$ (females, $1.6 \%$; males $0.5 \%$ ) was only educated up to primary level. Further $21.7 \%$ (females, $15.8 \%$; males $28.2 \%$ ) dropped from the school while insecondary level classes (i.e. grades 6 to 11). About 11.9\% (females, 9.3\%; males 14.8\%) passed the ordinary level examination and stopped schooling. Further $24.9 \%$ entered advanced level classes (females, $22.0 \%$; males $28.2 \%$ ), yet failed to pass the advanced level examination. Around 32.7\% (females, 39.8\%; males $24.5 \%$ ) had passed advanced level examination and the rest, $7.6 \%$ (females, $11.0 \%$; males $3.7 \%$ ), were in to higher education after their advance level. 
Of all youths ( $\mathrm{n}=925), 17.7 \%$ (females, $14.4 \%$; males $21.4 \%$ ) were having either a full or part time income generating activity. Their median monthly income was 10,200 Sri Lankan rupees and varied from 1,000 to 45,000 rupees. About 6 $\%$ of youths were living in the families that did not have a monthly income sufficient for providing basic meals to its members. Ninety six percent (females, 95.7\%; males 96.4\%) of them were living in parental residences.

\section{Physical health}

About 19.9\% (95\% CI: $17.3-22.5 \%)$ of youths, had suffered form an illness, which required them to avoid their daily engagements such as schooling, work, etc. during the month preceding the survey. The main form of illness reported was viral fever (16\%). Headache, dengue fever, asthma, accidental injuries were reported by less than $1 \%$ of youths respectively. The survey inquired whether the youth were informed by a medical practitioner about the presence of a several chronic illnesses among them. Asthma was present among 5.8\% (95\% CI: $4.3-7.4 \%$ ) youths and heart ailment was reported by $0.5 \%$ (95\% CI: $0.1-1 \%$ ) of them. Only $0.1 \%$, $0.2 \%$ of youths reported having diabetes and epilepsy respectively. Nearly $9 \%$ (95\% CI: 3.6 $6.4 \%$ ) of youth were having eye sight problem and $4 \%$ of them was using spectacles for this problem. Two percent (95\% CI: $0.9-2.7 \%)$ reported that they were having hearing difficulties. Survey inquired whether the youth had met with an accident, which required him or her to take treatment at an outpatient clinic or in a hospital as an inpatient. Five percent (95\% CI: $3.7-6.6 \%)$ of youths reported having met with such an accident with in the past 12 months preceding the survey. Nearly half (45\%) of these accidents were due to road traffic accidents. Falling from heights $(26 \%)$, sports injuries (13\%), injuries due to fighting with others $(8 \%)$ and burns $(2 \%)$ were reported as the major reasons for accidents.

\section{Mental health}

Youths' perceptions on general happiness, main worries, feeling the life is not worth living, suicidal feelings were studied as indicators reflecting mental health of them. During the preceding 2 weeks of inquiry, about $16 \% \quad(95 \%$ CI: $13.7-18.5 \%$ ) of youths were feeling not happy about the life due to some reason. Figure 1 presents the various reasons for unhappiness of them.

\section{Figure 1 Percentages distrbution of reasons for the $16 \%$ youths to be unhappy during preceding 2 weeks of inquiry}

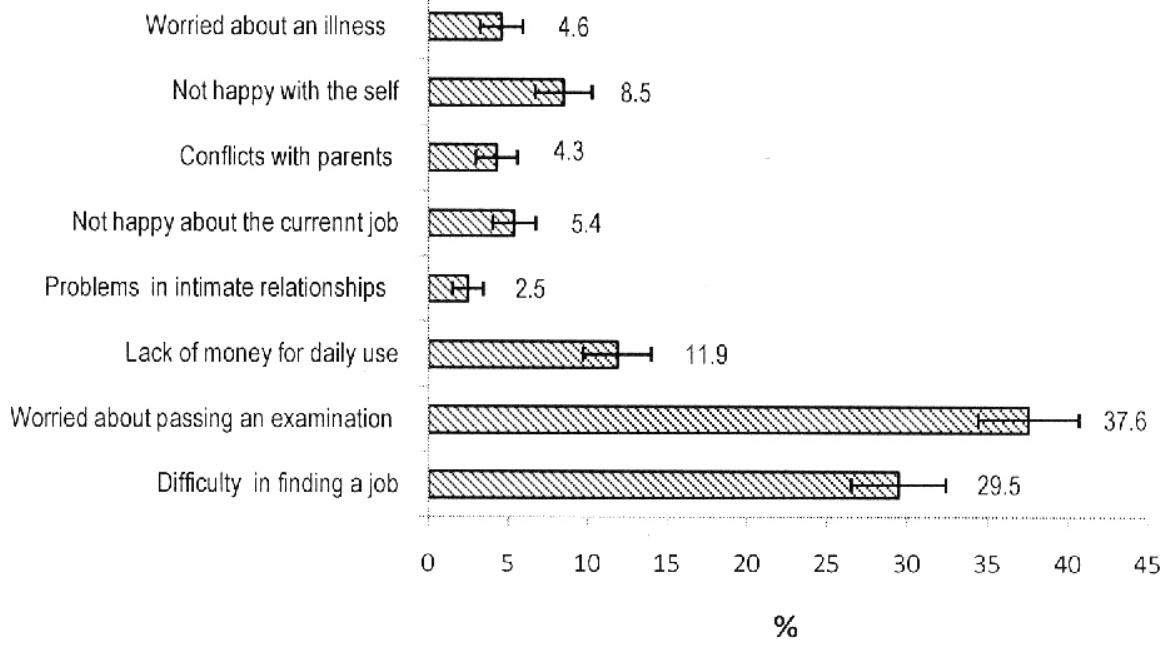


Sentiment that the life is not worth living, and having suicidal feeling reflect a significant mental health problem among a person. Approximately, $18.7 \%$ (95\% CI: 16.2 -21.2\%) youths had felt that life was not worth living, while $6 \%$ (95\% CI: 4.4-7.5\%) had strong suicidal feelings at least on one occasion during past 12 months.
Prevalence of substance abuse and sexuality related behaviors

Use of alcohol, smoking, and other abusive substances, intimate relationships, sexual behaviors, and exposure to various forms of abuses were enumerated in the survey. Table 1 presents the overall and gender based prevalence of these behaviors.

Table 1 : Prevalence of substance abuse behaviors among youth

\begin{tabular}{|l|c|c|c|}
\hline \multirow{2}{*}{$\begin{array}{l}\text { Type of substance abuse } \\
\text { behavior }\end{array}$} & \multicolumn{3}{|c|}{ Prevalence (95\% CI) (n=925) } \\
\cline { 2 - 4 } & Males & Females & $15.9(13.5-18.3)$ \\
\hline Ever smoking & $31.8(27.4-36.2)$ & $1.4(0.4-2.5)$ & $7.5(5.9-9.3)$ \\
\hline Smoking during past week & $15.9(12.4-19.3)$ & 0.0 & $6.3(4.8-8.0)$ \\
\hline $\begin{array}{l}\text { Chewing beetle and tobacco } \\
\text { during the past week }\end{array}$ & $12.5(9.4-15.6)$ & $0.08(0.01-0.16)$ & $19.9(17.3-22.5)$ \\
\hline Ever drinking alcohol & $37.8(33.2-42.5)$ & $3.2(1.6-4.8)$ & $30.7(23.2-36.9)$ \\
\hline $\begin{array}{l}\text { Alcohol use during the past } \\
\text { week }\end{array}$ & $37.2(25.3-40.1)$ & 0.0 & $12.7(10.6-14.9)$ \\
\hline $\begin{array}{l}\text { Ever use of other abusive } \\
\text { substances }\end{array}$ & $18.6(15.0-22.3)$ & $7.4(5.1-9.7)$ & \\
\hline
\end{tabular}

Considerable gender differences were seen among high risk behaviors. Smoking was seen as an almost exclusive male behavior, where nearly $32 \%$ and $16 \%$ males smoked ever and during the week preceding the survey respectively. Of those who smoked during the past week, around $36.7 \%$ were smoking daily and consumed around 2 cigarettes on a usual smoking day. Smoking among females was rare. Only $1.4 \%$ of female youths admitted having ever smoked. On average, the first smoke has taken place around 16 years ( $95 \%$ CI: $15.7-16.5$ years).
Alcohol use was also seemed to be predominantly a male behavior. Youths, who used alcohol seemed to have used it regularly, as indicated by more or less similar prevalence (around 37\%) of ever use of alcohol and alcohol use during the week preceding the survey. Average age at the first alcoholic drink was 16.4 years (95\% CI: 15.9 -16.9 years). Only $3.9 \%$ daily drinkers were present among those who drank alcohol during the week preceding the survey. 
Nearly, $18 \%$ male youths reported abusing narcotic substances. Unlike in the cases of smoking and alcohol use relatively larger percentage $(7.4 \%)$ of female youths had ever tried some form of abusive substances. "Madnana Modkaya" (37.2\%), Cannabis (31.2\%), Babul (24.5\%) Some form of medicinal drug obtained from a pharmacy (9.3\%), and Heroin (0.08\%) were the commonly abused substances among youth reporting narcotic substance abuse $(\mathrm{n}=118)$. Average age at initiating substance abuse was 16.7 years $(95 \%$ CI: $16.2-17.3$ years).

Several dimensions of intimate relationships, sexual behaviors and exposure to sexual abuse among youths were assessed in the survey.

Table 2 Prevalence of sexuality related behaviors among youths.

\begin{tabular}{|l|l|l|l|}
\hline \multirow{2}{*}{ Risk behavior / type of abuse } & \multicolumn{3}{|c|}{ Prevalence (95\% CI) (n=925) } \\
\cline { 2 - 4 } & Males & Females & All \\
\hline $\begin{array}{l}\text { Presently in an intimate } \\
\text { relationship }\end{array}$ & $37.6(33.0-42.3)$ & $37.0(32.6-42.4)$ & $37.3(34.1-40.5)$ \\
\hline Ever having sexual intercourse & $11.6(8.6-14.7)$ & $2.7(1.3-4.2)$ & $7.0(5.3-8.6)$ \\
\hline $\begin{array}{l}\text { Sexual intercourse within the } \\
\text { past year }\end{array}$ & $6.8(4.5-9.2)$ & $0.6(0.11 .3)$ & $3.6(2.4-4.8)$ \\
\hline $\begin{array}{l}\text { Had inter-crural sex within the } \\
\text { past year }\end{array}$ & $6.3(4.1(8.7)$ & $1.4(0.4-2.5)$ & $3.8(1.2-4.8)$ \\
\hline $\begin{array}{l}\text { Had oral sex within the past } \\
\text { year }\end{array}$ & $3.6(1.9-5.4)$ & $0.8(0.01-1.6)$ & $2.3(1.2-3.1)$ \\
\hline $\begin{array}{l}\text { Practice masturbation within } \\
\text { the past year }\end{array}$ & $33.7(29.3-38.1)$ & $1.4(0.4-2.5)$ & $16.8(14.3-19.2)$ \\
\hline $\begin{array}{l}\text { Used the internet for sexual } \\
\text { gratification within the past } \\
\text { year }\end{array}$ & $11.8(8.8-14.8)$ & $2.2(0.8-3.3)$ & $6.3(5.1-8.3)$ \\
\hline $\begin{array}{l}\text { Forced to have sex by someone } \\
\text { else }\end{array}$ & $3.5(1.8-5.3)$ & $2.5(1.1-3.9)$ & $2.9(1.9-4.1)$ \\
\hline $\begin{array}{l}\text { Experienced sexual advances } \\
\text { while using public transport }\end{array}$ & $3.9(2.1-5.7)$ & $14.6(11.5-17.6)$ & $9.5(7.6-11.4)$ \\
\hline
\end{tabular}

Of youths, around $38 \%$ were in an intimate relationships and on average they started these relationships around $17.2 \%$ (95\% CI: $16.8-17.4$ years) of age. Around $11.6 \%$ of male youths reported ever having sexual intercourse; while only $2.7 \%$ of female youths did so. The first sex was most commonly experienced with the intimate partner $(73 \%)$ while further $12 \%$ had experienced the sexual debut with a friend or a relative. The first sexual experiences of $10.6 \%$ of male youths were with commercial sex workers.
Another, $3.5 \%$ had the first sexual experience with incidental contacts. Only $58 \%$ of youths who had sexual intercourse during the past year used condoms. Prevalence of others forms of sexual acts were relatively lower except masturbation that was reported by nearly $17 \%$ of youths with a predominance among males ( $34 \%$ among males vs $1.4 \%$ among females). Use of internet for sexual gratification was reported by nearly $12 \%$ of youths, males taking the lead. Average age at having sexual debut was 18.1 years $(95 \%$ CI: 17.5 -18.8 years). 
Nearly $3 \%$ of youths reported that they were ever forced to have sex with someone. Relatively higher percentage of male youths $(3.5 \%)$ than female youths $2.5 \%$ had experienced such situations.

\section{Factors affecting substance abuse \& risk behaviors}

Binary logistic regression was used to determine the effects of selected influencing factors on the abusive behaviors "ever smoked", "ever drank alcohol", "ever used an abusive substance", and the risk of "ever having exposed to a sexual encounter". The influencing factors evaluated included the sex of the respondent, residential sector defined as urban and rural, family environment defined as very pleasant to live versus otherwise, socially active or not based on reported involvement in social actions by the youth, felt socially isolated based on whether having or not supportive figures other than the family, ever felt socially discriminated, proxy economic status of the family defined as the family's income during the last month was adequate to fulfill all routine needs versus otherwise, has own source of income or dependent on parents, and the level of reproductive knowledge defined as low and high based on the marks obtained for set of 32 questions dichotomized at its median. Reproductive knowledge was considered as a risk factor of ever having sex only.

Based on the likelihood ratio chi square tests, all 4 models were significant at $\mathrm{p}$ values less than 0.0001 for some selected variables. Models were considered to be adequate fit, whenever Hosmerb Lemeshow ChiSquare test based probability was more than 0.05 . Table 3 presents the factors that were found to be influencing different outcomes.

Table 3 Effects of selected factors influencing substance abuse and sexual behavior among youth

\begin{tabular}{|c|c|c|}
\hline Outcomes & $\begin{array}{l}\text { Influencing factors } \\
\text { (\# Reference category) }\end{array}$ & OR (95\% CI) \\
\hline \multirow{3}{*}{ Ever smoked } & Males vs. Females $\#$ & $25.6(11.6-56.6)$ \\
\hline & $\begin{array}{l}\text { Socially active vs. Socially not } \\
\text { active }\end{array}$ & $2.0(1.2-3.2)$ \\
\hline & $\begin{array}{l}\text { Has own income versus dependent } \\
\text { on parents }\end{array}$ & $3.4(2.2-5.3)$ \\
\hline \multirow{4}{*}{ Ever drank alcohol } & Males vs. Females $^{\#}$ & $14.3(8.1-25.2)$ \\
\hline & $\begin{array}{l}\text { Socially active vs. Socially not } \\
\text { active }\end{array}$ & $2.0(1.3-3.2)$ \\
\hline & Felt socially isolated vs. not ${ }^{\#}$ & $1.9(1.01-3.4)$ \\
\hline & $\begin{array}{l}\text { Has own income versus dependent } \\
\text { on parents } \#\end{array}$ & $3.2(2.1-4.8)$ \\
\hline \multirow{3}{*}{$\begin{array}{l}\text { Ever used an abusive } \\
\text { substance }\end{array}$} & Males vs. Females ${ }^{\#}$ & $2.5(1.6-4.0)$ \\
\hline & $\begin{array}{l}\text { Socially active vs. Socially not } \\
\text { active }\end{array}$ & $1.7(1.1-2.8)$ \\
\hline & $\begin{array}{l}\text { Has own income versus dependent } \\
\text { on parents } \#\end{array}$ & $3.0(1.9-4.6)$ \\
\hline \multirow{4}{*}{ Ever had sex } & Males vs. Females ${ }^{\#}$ & $3.7(1.9-7.2)$ \\
\hline & $\begin{array}{l}\text { Socially active vs. Socially not } \\
\text { active }\end{array}$ & $2.1(1.1-4.1)$ \\
\hline & $\begin{array}{l}\text { Has own income versus dependent } \\
\text { on parents } \#\end{array}$ & $4.9(2.7-8.7)$ \\
\hline & $\begin{array}{l}\text { High Knowledge vs. Low } \\
\text { Reproductive knowledge }\end{array}$ & $3.1(1.7-5.6)$ \\
\hline
\end{tabular}




\section{DISCUSSION}

National Youth Survey provides an opportunity to have insight on issues among Sri Lankan youths after nearly a decade. Such surveys was previously conducted in the year 2004 and 2008 $[6,10]$. This article only summarizes the status of Sinhalese Buddhist unmarried youths of whom the data was available at the time of writing. This stratum of youths comprises the majority of youths (77\%) in Sri Lanka.

The facts that nearly quarter of youths idle at home without engaging in education or gainful employment, nearly $6 \%$ of them were from homes that have got no income at least to bare basic needs and nearly $23 \%$ of youths were either never attended to a school or only educated up to the primary level are among the noteworthy socio demographic concerns surfaced from the study.

Youths studied seemed to be relatively physically healthy except for relatively smaller proportions reporting of having asthma (6\%), eye sight problems (9\%), and hearing difficulties. Around $5 \%$ of youths reported to have met with an accident that was severe enough to seek hospital treatment. Tough these figure are in relatively lower proportions, they represent a considerable disease burden when they are transferred to number of youths affected at national level. Mental health of youths seemed to have relatively poor outlook, when compared to their physical health. About $16 \%$ of them were not happy, $18 \%$ were

considering the life was not worth living and $6 \%$ has had strong suicidal feelings. The Global School Health Survey conducted in 2008 [10], revealed that $9.9 \%$ had seriously considered attempting suicide during the previous 12 months. The findings related to mental health are noteworthy in a context where deliberate selfharm is among the leading causes of deaths among youths in Sri Lanka.

The substance abuse seems to be predominantly a male behavior at present as it was in 10 years back. It was shown that percentage of ever smoking among males was 10 percent lower than the corresponding percentage, $42 \%$, in the last national survey in 2004 [6]. Prevalence of ever taking alcohol (38\%) also was shown to be lower than $49 \%$ recorded 10 years back. Prevalence of ever trying a mood altering drug however has shown a higher value, $18 \%$ compared to $6 \%$ in 2004. Prevalence of ever having sex has shown a lower value $12 \%$ compared to corresponding percentage of 27 in the last survey. About $10 \%$ of youths reported of having experienced their sexual debut with a commercial sex worker. All these indicators seem to be lower than that shown in US national surveillance report [4].

Gender, level of social involvements, having access to money seem to be common factors that increase youth risk behaviors. It is also interesting to note that having high reproductive health knowledge increased sexual behaviors. These are shown to be some of the main factors fostering risk behaviors elsewhere [13].

Though favorable trends are seen in some youth indicators such as smoking and alcohol use, there still seem to be a considerable burden of risk and ill-health among youths at present that should be addressed through a systematic youth health promotion programme.

Several strategic interventions related to the youth wellbeing were launched during past years in Sri Lanka. The National Youth Health Policy was launched. A pilot study on youth friendly health centers were initiated in selected Medical Officer of Health areas. Adolescent health strategic plan is currently under development. However, there seems to be a considerable delay in picking of the momentum to scale up of these initiatives. Many reasons can be identified for this inertia. One may be that subject matters and strategic interventions related to youth health promotion are not familiar to the current health workforce compared to the familiarity of such aspects related to its parallel areas such as 
maternal child health and family planning. Another difference of existing youth initiatives from other primary health care programmes is that they tend to be implemented as isolated projects rather than programmes mainstreamed to primary health care system. So far there is no mechanisms set in place to systematically cover all youths in different areas of the country. One such potential mechanism, the national school health programme, should be utilized for introducing reproductive health knowledge and services to the maximum extent possible. The youth friendly health services should be systematically scaled up in to all $\mathrm{MOH}$ areas of the country and a systematic approach should be adopted to ensure all youth required such services are covered by those.

\section{CONCLUSIONS}

A considerable proportion of youth were not gainfully occupied. Substance abuse and Mental health problems among adolescents seemed to be more prevalent than physical health problems therefore needs attention. Being a male, having own income, and being socially active seem to increase the youths vulnerability to risk behaviors.

This study was funded by UNICEF Colombo and UNFPA Colombo

\section{REFERENCES}

1. UNESCO. What do we mean by youth? [cited 2013 Oct 4]; Available from: http://www.unesco.org/new/en/social-andhuman-sciences/themes/youth/youthdefinition/

2. Index Mundi. Sri Lanka demographic profile 2013. 2013 [cited 2013 Oct 4]; Available from: http:// www.indexmundi. com/sri lanka/demographics_profile.html

3. Department of Census and Statistics Sri Lanka. Population Charactersitics [cited 2013 Oct 4]; Available from: http://www.statistics.gov.lk/PopHouSat/ Pop_Chra.asp
4. U.S. Department of Health and Human Services, Youth Risk Behavior Surveillance United States, 2011. Surveillance summaries -MMWR, 2012.61(4):p. 1-2.

5. MacPherson, L., et al., Positive and negative reinforcement underlying risk behavior in early adolescents. Preventive Science 2010. 11(3): p. 331-342.

6. Thalagala, N.I. and L. Rajapakse. National survey on emrging issues among adolescents in Sri Lanka. 2004 [cited 2013 Oct 4]; Available from: http:// www.unicef. org /srilanka/Full_Report.pdf

7. Thalagala, N.I., The prevalence \& risk factors of risk behaviours among late adolescents (17-19 years) in Sri Lanka. Marga Journal, 2008(Special issue- March ): p. 151-162.

8. UNFPA. Framework for Action on Adolescents and Youth. 2007 [cited 2013 Oct 5]; Available from: https:// www.unfpa.org/webdav/site/global/ shared/documents/publications/2007/ framework youth.pdf

9. UNFPA. Generation of Change: Young People and Culture. 2008 [cited 2013 Oct 6]; Available from: http://www.unfpa.org /swp/2008/en/youth_preface_introduction.h $\underline{\mathrm{tml}}$

10. CDC. Global School-based Student Health Survey 2008 Fact Sheet, Sri Lanka. 2008 [cited 2013 Dec 19]; Available from: http://www.who.int/chp/gshs/Sri_Lanka_G SHS_FS_2008.pdf.

11. Lauritsen, J., EpiData Data Entry, Data Management and basic Statistical Analysis System. 2008, EpiData Association: Odense Denmark.

12. StataCorp, Stata Statistical Software: Release 10. 2007, StataCorp LP: College Station, Texas.

13. Path finder International (2004) [cited 2013 Nov 30$]$; Available from: http://www2.pathfinder.org/site/ DocServer/\%20\%20YFS_TG_Final_web version.pdf?docID $=762$ 